\title{
Advancing the remote sensing of desert dust
}

\section{Vassilis Amiridis, Alexandra Tsekeri, Eleni Marinou, Emmanouel Proestakis, Antonis Gkikas, et al.}

Vassilis Amiridis, Alexandra Tsekeri, Eleni Marinou, Emmanouel Proestakis, Antonis Gkikas, Anna Gialitaki, Vassiliki Daskalopoulou, Peristera Paschou, Nikos Siomos, loannis Binietoglou, Josef Gasteiger, Volker Freudenthaler, Rodanthi-Elisaveth Mamouri, Albert Ansmann, Lucia Mona, "Advancing the remote sensing of desert dust," Proc. SPIE 11152, Remote Sensing of Clouds and the Atmosphere XXIV, 1115206 (9 October 2019); doi:

$10.1117 / 12.2530322$

SPIE. Event: SPIE Remote Sensing, 2019, Strasbourg, France 


\title{
Advancing the remote sensing of desert dust
}

\author{
Vassilis Amiridis*a, Alexandra Tsekeri ${ }^{\mathrm{a}}$, Eleni Marinou ${ }^{\mathrm{a}}$, Emmanouel Proestakis $^{\mathrm{a}}$, Antonis Gkikas ${ }^{\mathrm{a}}$, \\ Anna Gialitaki ${ }^{\mathrm{a}}$, Vassiliki Daskalopoulou ${ }^{\mathrm{a}}$, Peristera Paschou ${ }^{\mathrm{a}}$, Nikos Siomos ${ }^{\mathrm{a}}$, Ioannis Binietoglou ${ }^{\mathrm{b}}$, \\ Josef Gasteigerc ${ }^{\mathrm{c}}$, Volker Freudenthaler ${ }^{\mathrm{d}}$, Rodanthi-Elisaveth Mamouri ${ }^{\mathrm{e}}$, Albert Ansmann ${ }^{\mathrm{f}}$, Lucia \\ Mona $^{\mathrm{g}}$

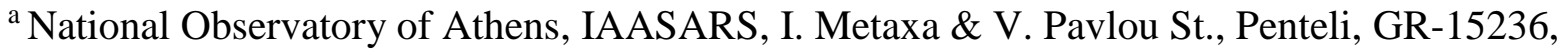 \\ Greece; ${ }^{b}$ Raymetrics S.A., 32 Spartis, Metamorfosis 14452, Athens, Greece; ${ }^{c}$ Faculty of Physics, \\ University of Vienna, Vienna, Austria, ${ }^{\mathrm{d}}$ Fakultät für Physik, Meteorologisches Institut, Ludwig- \\ Maximilians-Universität, Munich, Germany, ${ }^{e}$ Cyprus University of Technology, Limassol, Cyprus; \\ ${ }^{\mathrm{f}}$ Leibniz Institute for Tropospheric Research, Leipzig, Germany; ${ }^{\mathrm{g}}$ Consiglio Nazionaledelle \\ Ricerche, Istituto di Metodologie per l'Analisi Ambientale, Potenza, Italy
}

\begin{abstract}
The irregular shape of mineral dust provides a strong signature on active and passive polarimetric remote sensing observations. Nowadays, advanced lidar systems operating in the framework of ACTRIS are capable of providing quality assured, calibrated multi-wavelength linear particle depolarization ratio measurements, while new developments will provide us more polarimetric measurements in the near future. Passive polarimeters are already part of ACTRIS and their integration in operational algorithms is expected in the near future. This wealth of new information combined with updated scattering databases and sophisticated inversion schemes provide the means towards an improved characterization of desert dust in the future.

We present here some examples from the ACTRIS journey on dust research during the last decade, aiming to demonstrate the progress on issues such as: (a) the discrimination of desert dust in external mixtures, (b) the separation and estimation of the fine and coarse particle modes, (c) the synergy of passive and active remote sensing for the derivation of dust concentration profiles, (d) the provision of dust-related $\mathrm{CCN}$ and IN particle concentrations for aerosol-cloud interaction studies, (e) the development of new scattering databases based on realistic particle shapes, (e) the application of these techniques on spaceborne lidar retrievals for the provision of global and regional climatological datasets. Future plans within ACTRIS for the evaluation and advancement of the methodologies and retrievals are also discussed, combined with new developments within the framework of the D-TECT ERC Grant.
\end{abstract}

Keywords: Desert dust, polarization

*vamoir@ noa.gr; phone +302108109116; fax +30 210 6138343;

\section{INTRODUCTION}

Mineral dust is one of the most important aerosol types in terms of mass and optical depth and therefore significantly impacts radiation, either through direct or indirect processes, and subsequently atmospheric dynamics from short- to long-term temporal scales. Once dust particles are deposited at the surface, they provide micro nutrients to the ocean or to land ecosystems. For these reasons, the recent report of the IPCC identified mineral dust and its impacts on weather, climate and biogeochemistry as key topics for future research (see also Figure 1).

Pure dust is difficult to be detected and measured, except in very specific areas close to deserts. In outflow regions, mineral dust coexist with other particles like smoke or sea salt and pollution. Accurate speciation is a main observational need to efficiently characterize desert dust abundances and intensive properties so as to assess the related impacts. 


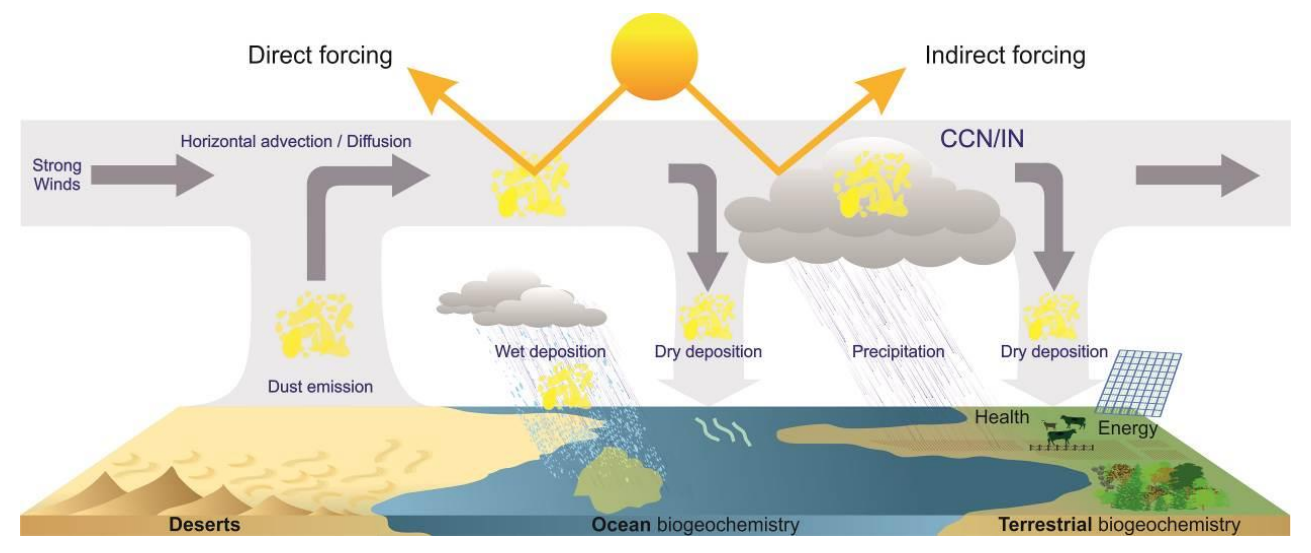

Figure 1. Schematic of long-range dust transport and its impacts on climate and biogeochemistry

Despite the limitations on speciation, remote sensing has been applied from both ground and space to describe the global distribution and characteristics of atmospheric dust. For assessing the dust abundances the Dust Aerosol Optical Depth (DOD) needs to be derived from measurements of the total Aerosol Optical Depth (AOD). Currently, in order to discriminate between dust and other aerosol types with existing remote sensors, typical features of dust are used such as: (1) dust dominated coarse mode that affects the Angström exponent values (a threshold that can be applied in spectral AOD measurements); (2) dust particle non-sphericity that provides a clear signature in depolarization measurements of the backscattered light.

\section{ADVANCED DUST REMOTE SENSING PRODUCTS}

One example of pure DOD and dust extinction profiling product retrievals is the LIdar climatology of Vertical Aerosol Structure for space-based lidar simulation studies (LIVAS) study of the European Space Agency (ESA), using CALIPSO backscatter and depolarization products in synergy with the ground-based typical values of mineral particle depolarization and lidar ratios derived from EARLINET [1]. LIVAS is based on the application of Tesche et al. [2] methodology for the discrimination of pure dust from dust mixtures using backscatter and depolarization lidar measurements (Figure 2).
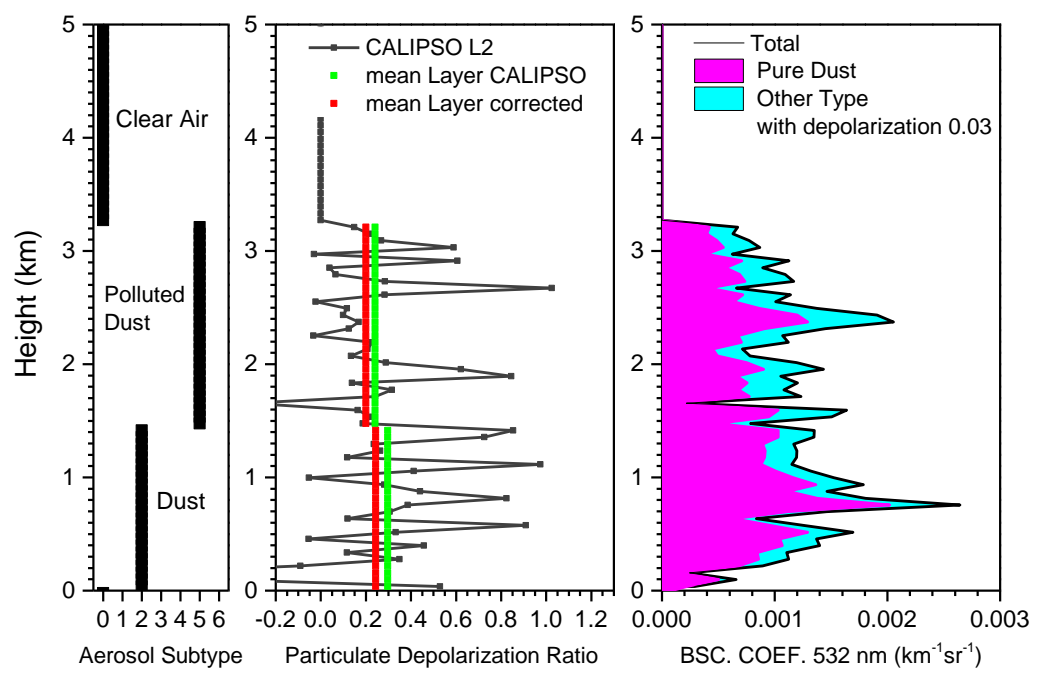

Figure 2. (Left:) aerosol type. Middle: particle depolarization ratio (black line), mean layer depolarization reported by CALIPSO (green line) and mean particle depolarization ratio recalculated by the mean layer total and perpendicular backscatter coefficients (red line). (Right:) backscatter coefficient separation for pure dust (in magenta color) and "other" aerosol type (in cyan color). 
LIVAS provides pure dust extinction profiles with a resolution of $1 \mathrm{x} 1$ degree, based on CALIPSO. An example of this product over China is given in Figure 3, where the seasonal mean for total AOD, DOD and non-dust AOD is given for spring. DOD values are higher over Taklimakan desert while the anthropogenic aerosol loads dominate over the eastern and south-eastern regions of the Asian continent [3].
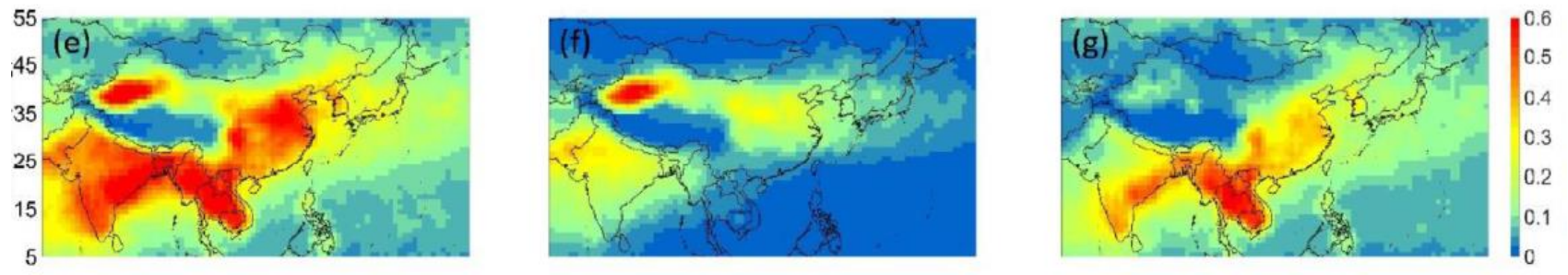

Figure 3. Spatial distribution of the seasonal mean CALIPSO AOD, DOD, optical depth difference between AOD and D_AOD (non-dust AOD) for the spring period (means for the period 2007-2015).

Another example of LIVAS, showing the potential to use the vertical distribution of dust extinction in order to study dust transport is given in Marinou et al. [4] (Figure 4).
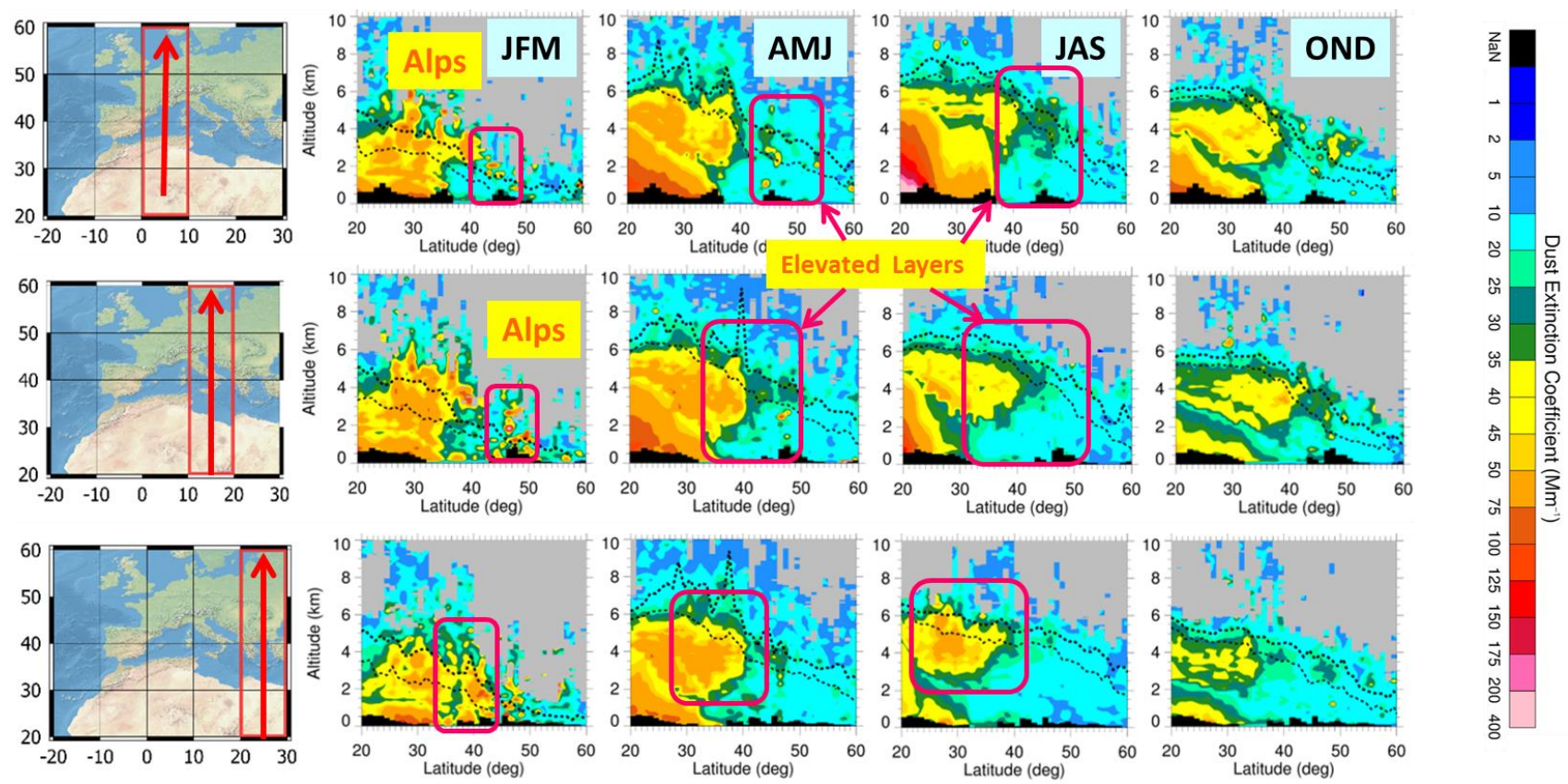

Figure 4. Geographical zonal distribution of the conditional dust extinction coefficient LIVAS product for the latitudinal zones from $20 \mathrm{~N}$ to $60 \mathrm{~N}$ as illustrated by domain maps for the 3-monthly averages. The median terrain elevation is depicted with black color.

Advanced algorithms are being developed within the framework of the ACTRIS Research Infrastructure, including inversion schemes such as GARRLiC [5], LIRiC [6] and POLIPHON [7]. These algorithms provide the opportunity to retrieve dust microphysical properties but also separate the fine from the coarse modes. Moreover, recent advancements in ACTRIS include the retrieval of dust CCN and IN particle concentrations from remote sensing [8; 7; 9]. By applying these methods to available space-borne lidar products, one can retrieve important information on desert dust features and distribution that were not available before (see for example Figure 5, 6). 


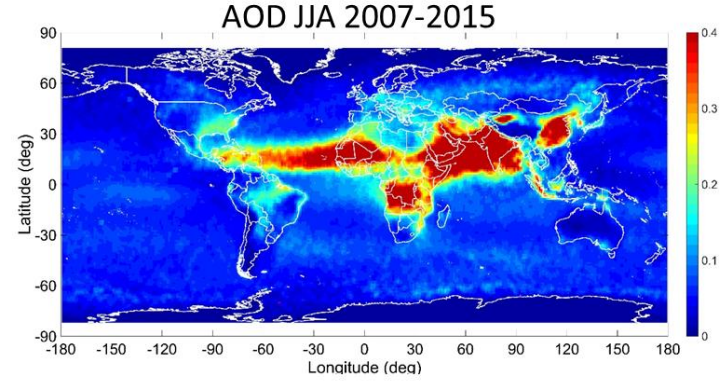

Coarse Dust OD JJA 2007-2015

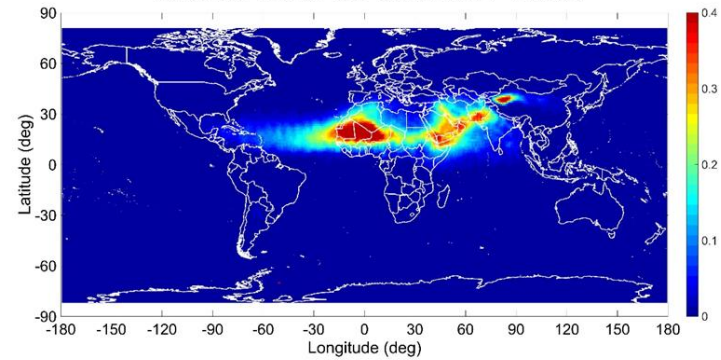

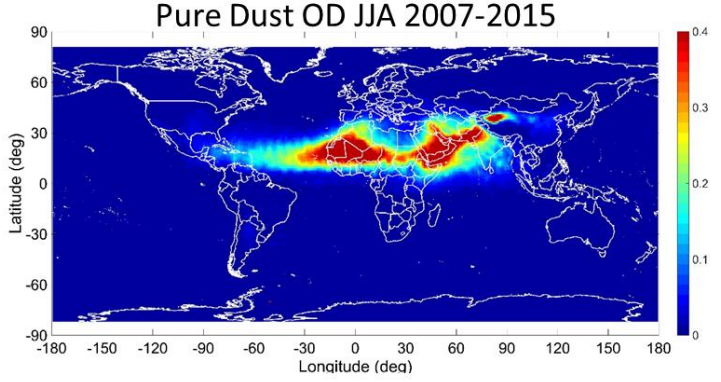

Fine Dust OD JJA 2007-2015

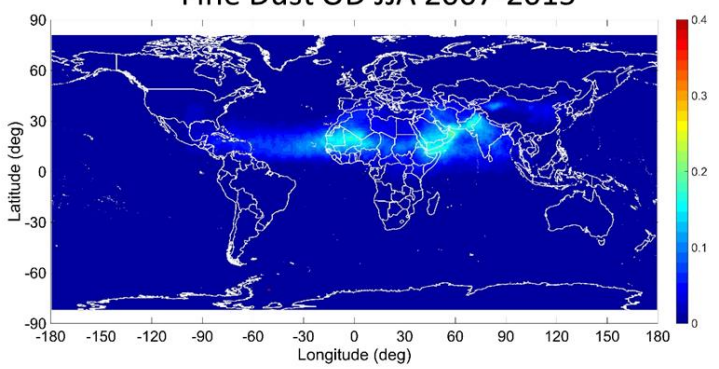

Figure 5. Geographical distribution of the AOD, DOD and Coarse DOD, Fine DOD.
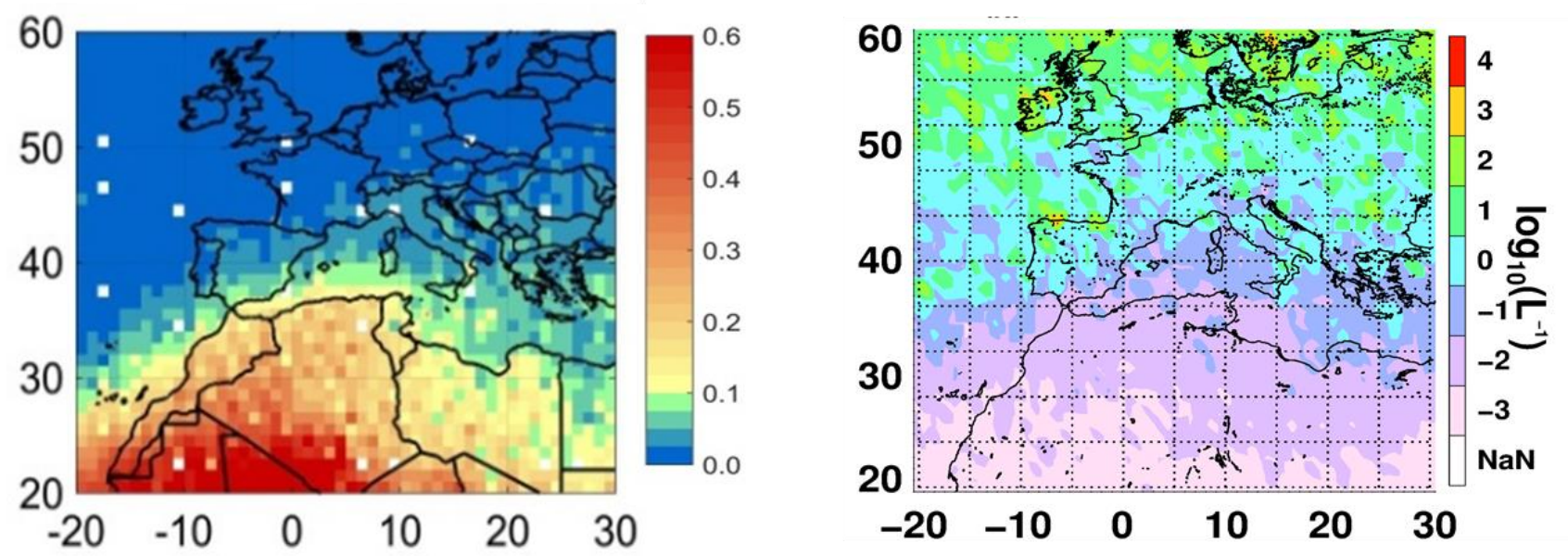

Figure 6. Geographical distribution of the DOD and Ice Nuclei Particle concentrations.

\section{FUTURE PERSPECTIVES}

Speciation and advanced aerosol characterization through remote sensing is difficult and requires observations beyond intensity-only measurements. In that respect, multi-angle measurements of intensity and polarization should be considered for improving dust characterization (e.g. $[10 ; 11])$. Such measurements can also provide information on the preferential orientation of the mineral particles during their transport [12]. Polarization however depends strongly on particle shape $[13 ; 14]$ and its interpretation is tricky for dust due to lack of adequate scattering models for large irregularly-shaped particles. 
To improve the scattering models for desert dust, realistic representations of the particles' irregular shapes have been proposed (e.g. [14]). Recent work by Tsekeri et al. [15] extends the scattering calculations of Gasteiger et al. [14] to particles with volume-equivalent size parameters up to 60 , using the extensive computational resources of Partnership for Advanced Computing in Europe (PRACE). Moreover, new polarization techniques are developed for passive sensors (see [11]) but also for active sensors such as lidars [15]. Figure 7 shows the new polarization lidar "WALL-E" designed to monitor dust orientation in the atmosphere. The new scattering databases and polarization sensors are expected to increase information on dust and reveal its radiative characteristics in respect to their shape and size.

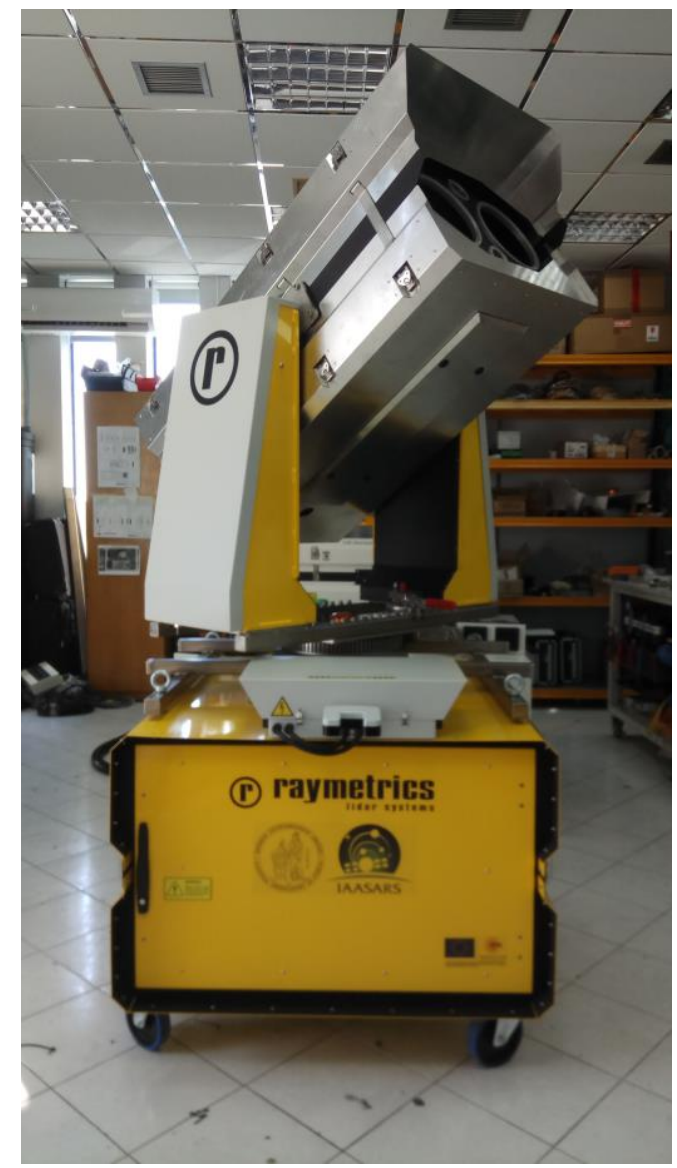

Figure 7. The WALL-E polarization lidar system for the detection of preferential particle orientation.

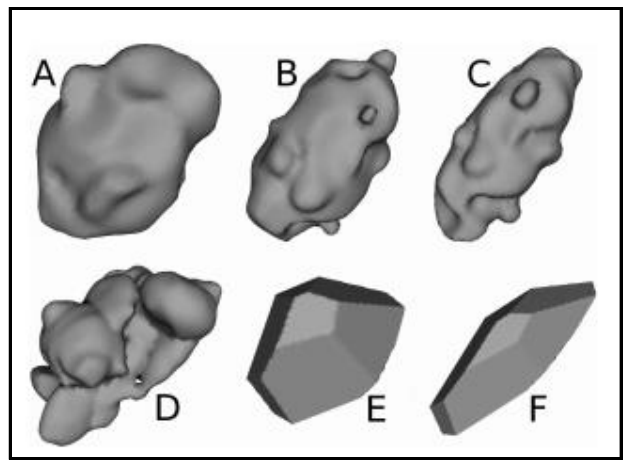

Figure 8. Particle shapes considered for the new scattering database of Tsekeri et al. [15] (source: [14]). 


\section{ACKNOWLEDGMENTS}

The research leading to these results has received funding from the European Research Council (ERC) project D-TECT (Does dust triboelectrification affect our climate?) under grant agreement no. 725698 and the European Union's Horizon 2020 research and innovation program ACTRIS-2 (Aerosols, Clouds and Trace gases Research InfraStructure Network) under grant agreement no. 654109. The authors affiliated to National Observatory of Athens acknowledge support through the Stavros Niarchos Foundation. We acknowledge PRACE for awarding us access to MareNostrum at

Barcelona Supercomputing Center (BSC), Spain. The work was supported by computational time granted from the Greek Research \& Technology Network (GRNET) in the National HPC facility - ARIS - under project ID pa170906ADDAPAS and pr005038-REMOD.

\section{REFERENCES}

[1] Amiridis, V., Marinou, E., Tsekeri, A., Wandinger, et al., "LIVAS: a 3-D multi-wavelength aerosol/cloud database based on CALIPSO and EARLINET", Atmos. Chem. Phys., 15, 7127-7153, (2015).

[2] Tesche, M., Ansmann, A., Müller, D., Althausen, D., Engelmann, R., Freudenthaler, V. and Groß, S., "Vertically resolved separation of dust and smoke over Cape Verde using multiwavelength Raman and polarization lidars during Saharan Mineral Dust Experiment 2008”, J. Geophys. Res., 114, D13202, (2009).

[3] Proestakis, E., Amiridis, V., Marinou, E., Georgoulias, A. K., et al., "Nine-year spatial and temporal evolution of desert dust aerosols over South and East Asia as revealed by CALIOP", Atmos. Chem. Phys., 18, 1337-1362, (2018).

[4] Marinou, E., Amiridis, V., Binietoglou, I., Tsikerdekis, A., et al., "Three-dimensional evolution of Saharan dust transport towards Europe based on a 9-year EARLINET-optimized CALIPSO dataset”, Atmos. Chem. Phys., 17, 5893-5919, (2017).

[5] Lopatin, A., Dubovik, O., Chaikovsky, A., Goloub, P., Lapyonok, T., Tanré, D. and Litvinov, P., "Enhancement of aerosol characterization using synergy of lidar and sun-photometer coincident observations: the GARRLiC algorithm", Atmos. Meas. Tech., 6, 2065-2088, (2013).

[6] Chaikovsky, A., Dubovik, O., Holben, B., Bril, A., et al., "Lidar-Radiometer Inversion Code (LIRIC) for the retrieval of vertical aerosol properties from combined lidar/radiometer data: development and distribution in EARLINET”, Atmos. Meas. Tech., 9, 1181-1205, (2016).

[7] Ansmann, A., Mamouri, R.-E., Hofer, J., Baars, H., Althausen, D. and Abdullaev, S. F., "Dust mass, CCN, and INP profiling with polarization lidar: Updated POLIPHON conversion factors from global AERONET analysis", Atmos. Meas. Tech. Discuss., in review, (2019).

[8] Mamouri, R.-E. and Ansmann, A., "Potential of polarization lidar to provide profiles of CCN- and INP-relevant aerosol parameters", Atmos. Chem. Phys., 16, 5905-5931, (2016).

[9] Marinou, E., Tesche, M., Nenes, A., Ansmann, A., et al.: Retrieval of ice nucleating particle concentrations from lidar observations: Comparison with airborne in-situ measurements from UAVs, Atmos. Chem. Phys. Discuss., https://doi.org/10.5194/acp-2018-1203, in review, 2018.

[10] Chowdhary, J., Cairns, B., Mishchenko, M. and L. Travis, "Retrieval of aerosol properties over the ocean using multispectral and multiangle photopolarimetric measurements from the Research Scanning Polarimeter", Geophys. Res. Lett., 28, 243-246, (2001).

[11] Dubovik, O., Li, Z., Mishchenko, M.I., Tanré, D., et al., "Polarimetric remote sensing of atmospheric aerosols: instruments, methodologies, results, and perspectives". J. Quant. Spectrosc. Radiat. Transfer, 224, 474-511, (2019).

[12] Ulanowski, Z., Bailey, J., Lucas, P. W., Hough, J. H. and Hirst, E., "Alignment of atmospheric mineral dust due to electric field", Atmos. Chem. Phys., 7, 6161-6173, (2007).

[13] Dubovik, O., Sinyuk, A., Lapyonok, T., Holben, B. N., et al., "Application of spheroid models to account for aerosol particle nonsphericity in remote sensing of desert dust", J. Geophys. Res., 111, D11208, (2006).

[14] Gasteiger, J., Wiegner, M., Groß, S., Freudenthaler, V., Toledano, C., Tesche, M. and Kandler, K., "Modeling lidarrelevant optical properties of complex mineral dust aerosols", Tellus B, 63, 725-741, (2011).

[15] Tsekeri, A., Freudenthaler, V., Doxastakis, G., Gasteiger, J., Louridas, A., Georgoussis, G., Binietoglou, I., Georgiou, T., Ulanowski, J. and Amiridis, V., "Polarization lidar for detecting dust orientation", Proceedings of the 29th International Laser and Radar conference, June 24-28, Hefei, Anhui, China (2019). 